\title{
Ueber die Einwirkung der Salpetersäure auf Fett-
}

\author{
säure; \\ von Ad. Schlieper.
}

In allen chemischen Lehrbüchern wird angeführt, dafs die Fellsäure durch Kochen mit Salpetersäure keine Veränderung erleide; die Aehnlichkeit, welche dieselbe aber in vielen ihrer physikalischen Eigenschaften mit der Benzoësäure zeigt, liefs der Vermuthung Raum, dafs sie sich auf ähnliche Weise wie die letztere durch Einwirkung starker Salpetersäure in eine Nitrofettsäure $\mathrm{C}_{20}{\stackrel{\mathrm{NO}}{\mathrm{N}_{4}}}_{\mathrm{H}_{7}}^{\mathrm{O}_{3}}$ verwandeln lasse. Auf jeden Fall war es interessant, zu erfahren, ob die Einwirkung der Salpetersäure auf dieses constante Zerselzungsproduct der Oelsäure in erhöhter Temperalur nicht die Erzeugung von einer oder mehreren der Säuren veranlafsle, welche $L$ a u rent durch directe Einwirkung dieses Agens auf Oelsäure hervorgebracht hat.

Die zu diesem Versuche dienende Fettsäure wurde durch. Destillation der rohen, im Handel vorkommenden Oelsäure erhallen; das rohe Destillat wurde zu wiederholten Malen mit Wasser ausgekoclit, die wässerigen Auszüge mit $\mathrm{NaO} \mathrm{CO}_{2}$ gesältigt und zur 'Trockne verdamplt; zur Entfernung des caprylund caprinsauren Natrons wurde die trockne Salzmasse sodann mit heifsem absoluten Alkohol erschöpft, welcher das feltsaure Natron ungelosst lälst. Letzteres wurde sodann in Wasser gelöst und die Feltsäure mit Salzsäure ausgefällt; dieselbe wurde durch mehrmaliges Umkrystallisiren aus Wasser gereinigt und stellte nach dem Trocknen eine lockere, sehr leichte, weilse, aus kleinen glänzenden Krystallschüppchen bestehende Masse dar.

Um die Bildung einer Nitrofettsüure zu prüfen, wurde ein Theil Fettsäure mit 20-30 Theilen roher käuflicher Salpetersäure von 1,4 spec. Gew, in einem Kolben erwärmt; in der 
Kälte findeł keine Lösung statt, welche jedoch kurz vor dem Siedepuncte vollständig erfolgt, zu gleicher Zeit deuten die entstehenden rothen Dämpfe von $\mathrm{NO}_{4}$ und die orangenrothe Farbe, welche die Flüssigkeit annimmt, eine Zersetzung der Fellsäure an. Die salpetersaure Lösung wurde nun auf dem Sandbade in continuirlichem gelinden Sieden erhalten, so dals die verdampfende Salpetersäure sich zum gröfsten Theil in dem langen Kolbenhalse condensirte und zurückflo[s. Nach 2-3stündigem Sieden wurde ein kleiner Theil der heifsen salpetersauren Lösung ausgegossen, um zu untersuchen, ob die Bildung einer Nitrofettsäure staltgefunden habe, obgleich die fortwährende, jedoch sehr langsame Entwicklung von rothen Dämpfen zur Genüge anzeigte, dafs die Zersetzung noch nicht beendet sey.

Die heifse, salpetersaure Lösung, mit dem 8-10fachen Volum kalten Wassers vermischt, schied eine grofse Menge allem Anscheine nach unveränderte Feltsäure aus, dieselbe zeigte nach dem Auswaschen der Salpetersäure und Trocknen alle plyysikalischen Eigenschaften derselben. Zur gröfsern Sicherheil habe ich das Silbersalz der so erhaltenen Säure dargestellt und analysirt, woraus sich dann ergab, dafs es reine Fettsäure war.

$0,312 \mathrm{Grm}$. des Silbersalzes gaben $0,161 \mathrm{Ag}$, was einem Silberoxydgehalt von 55,41 pC. entspricht.

Feltsaures Silber enthält $55,76 \mathrm{pC}$. Silberoxyd.

Die Nichterzeugung einer Nitrofeltsäure auf diesem Wege ist also unzweifelhaft.

Ich möchte hier nicht unerwähnt lassen, dafs es wohl keine leichtere Methode gibt, die gewöhnlich etwas gelblich weifs gefarbte Fettsäure schneeweifs, gut krystallisirt und vollkommen rein zu erhalter, als die Behandlung mit Salpetersäure, welche fast mil gar leinem Verluste verknüpft ist. Es genügt, die unreine Feltsäure mil der 5-6fachen Menge oder mehr Salpetersäure eben aufzukochen und dic Lösung mit einer grofsen 
Menge siedenden Wassers zu vermischen; beim Erkalten krystallisirt die Feltsäure dann vollkommen rein heraus.

Der übrige Theil der Lösung von Feltsäure in Salpetersäure wurde bis zum Aufhören der Stickoxydgasentwickelung unter beständiger Erneuerung der verdampfenden Salpetersäure in beständigem Sieden erhalten; die Oxydation der besagten Säuro geht äufserst langsam von Statten, dieselbe nahm für eine Quantität von $15 \mathrm{Grm}$. Fetlsäure acht Tage in Anspruch. Nachdem die gelbe Farbe der Flüssigkeit sich in eine fast weifse verwandelt hatte und die Entwickelung des Stickoxydgases vollkommen aufgehört halte, wurde der Inhalt des Kolbens in eine flache Schaale ausgegossen, mit dem gleichen Volum Wasser vermischt und auf dem Wasserbade, unler beständigen kleinen Zusälzen von Wasser, die Salpetersäure allmählig abgelrieben; der weifse Rückstand wurde in Wasser gelöst, filtrirt und auf dem Wasserbade zum Syrup eingedampft; hierauf zum Krystallisiren über Schwefelsäure gestellt.

Regelmäfsige Krystalle konnten nicht erhalten werden; vielleicht, dafs die Menge der, der Krystallisation überlassenen Flüssigkeit nicht hinreichend war, sondern die ganze Flüssigkeit erstarrte sehr bald $\mathrm{zu}$ einer weifsen, bröckeligen, krystallinischen, etwas klebenden Masse, von ungefähr dem Ansehen des auf eben diese Weise krystallisirten reinen Traubenzuckers. Diese Substanz ist eine starke Säure, und zwar im vollkommen reinen Zustande und das einzige Product, was bei der Einwirkung der Salpetersäure auf Feltsäure entsteht. Dieselbe hat, wie sich gleich ergeben wird, gleiche Zusammensetzung und vollkommen gleiche Eigenschaften mil der Brenzzoeinsäure, so weit nämlich eine Vergleichung mit den schwankenden Angaben, die wir über die letzlere besilzen, möglich war.

Zur Analyse wurde die Säure über Schwefelsäure getrocknet und dann geschmolzen, wobei sie aber nicht mehr an Gewicht 
verlor; dieselbe wurde mit chromsaurem Bleioxyd verbrannt und gab folgende Resultate :

1) 0,349 Grm. Substanz gaben 0,579 Kohlensäure und 0,1915 Wasser.

2) 0,3293 Grm. Substanz gaben 0,5485 Kohlensäure und 0,1805 Wasser.

Hieraus berechnet sich die Formel :

$\mathrm{C}_{6} \mathrm{H}_{4} \mathrm{O}_{4}=\mathrm{C}_{5} \mathrm{H}_{3} \mathrm{O}_{3}$, $\mathrm{HO}$ Brenzweinsäurehydrat.

\begin{tabular}{|c|c|c|c|c|}
\hline \multicolumn{3}{|c|}{ berechnet } & \multicolumn{2}{|c|}{ gefunden } \\
\hline $\mathrm{C}_{5}$ & 375 & 45,45 & 45,27 & 45,42 \\
\hline $\mathrm{H}_{4}$ & 50 & 6,06 & 6,09 & 6,09 \\
\hline $\mathbf{O}_{4}$ & 400 & 48,49 & 48,64 & 48,49 \\
\hline $\mathrm{C}_{5} \mathrm{H}_{4} \mathrm{O}_{4}$ & 825 & 100 & 100 & 100. \\
\hline
\end{tabular}

Hiernach nimmt 1 Aequivalent Fettsäure bei der Oxydation mit Salpetersäure, 5 Aeq. Sauerstoff auf und verwandelt sich in 2 Aequivalente Pyroweinsäurehydrat.

1 Aeq. Fettsäure $\quad=\mathrm{C}_{10} \mathrm{H}_{8} \mathrm{O}_{3}$

$5 \Rightarrow \frac{\text { Sauersioff }}{\text { Brenzweinsäurehydr. }=\mathrm{C}_{10} \mathrm{H}_{8} \mathrm{O}_{8}=2\left(\mathrm{C}_{3} \mathrm{H}_{3} \mathrm{O}_{3}, \mathrm{HO}\right) .}$

Diese Säure unterscheidet sich demnach von der ihr in manchen Eigenschaften ähnelnden Lipinsäure durch ein Aeq. Sauerstoff, was die letztere mehr hat.

Die in Rede stehende Säure hat folgende Eigenschaften, welche fast ganz übereinstimmen mit den Angaben von Pelouz e über die Brenzweinsäure; die sehr geringen Abweichungen in Bezug auf das Krystallisationsverinögen der Säure waren mir durch die kleine Menge der Säure, die mir zu Gebote stand, nicht möglich auszugleichen.

Die Säure stellt, wie erwähnt, eine vollkommen weilse, krystallinische, ein wenig zusammenbackende Masse dar, durchaus luftbeständig, in einem Wasserbade erhitzt kam dieselbe in einen balbflüssigen Zusland, wenige Grade über 100 schmolz 
dieselbe jedoch zu einer wasserklaren Flüssigkeit, beim Erkalten zu einer krystallinischen Masse erslarrend. Vorsichtig auf einem Platinblech erhitzt, verflüchligt sich dieselbe vollkommen ohne Rückstand, mil Verbreilung eines weifsen erstickenden Dampfes. Zwischen zwei Uhrgläsern erhitzt, sublimirt dieselbe unter $\mathrm{Zu}$ rücklassung eines kohligen Rückstandes in stark glänzenden prismatischen Nadeln, welche alle Reaclionen der unsublimirten Säure zeigen. Die Säure ist geruchlos und hat einen stark sauren Geschmack, zum Verwechseln ähnlich mit dem eigenthümlich sauren Geschmack der Bernsteinsäure. Sie löst sich leicht in Wasser, Alkohol und Aether, ebenso in concentrirter Schwefelsäure ohne Schwärzung auf. Mit Schwefelsäure und Alkohol erwärmt älherificirt sich dieselbe leicht und bildet einen Aether von eigenthümlich aromalischem Geruch. Die wässerige Lösung Ireibt unter Aufbrausen Kohlensäure aus und gibt mit Ammoniak, Kali und Natron, wenn schnell abgedampft wird, gummiähnliche Salze, deren Lösungen aber in concentrirten Zustande über Schwefelsäure der Verdampfung überlassen, zu krysłallinischen Massen eintrocknen. Das Ammoniaksalz wird beim Abdampfen sauer. Die Salze der Alkalien sind in Weingeist löslich, sie geben mit Kalk - und Barytsalzen keine Niederschläge, mit Eisenchlorid einen flockigen bräunlichrothen Niederschlag, in ziemlich vielem kochenden Wasser löslich. Mit Kupfersalzen entsteht eine hellgrïne Fällung. Mit essigsaurem Bleioxyd entsteht kein Niederschlag, erst nach einigen Stunden setzt das Gemisch der nicht zu verdïnnten Lösungen ein weilses körniges Bleisalz ab, vorzüglich un den Wänden des Glases; einmal abgeschieden löst dasselbe sich sehr schwierig in Wasser. Setzt man der gemischlen Lösung sogleich Alkohol zu, so erfolgt sogleich ein weifser Niederschlag, beim Erhitzen zu ölartigen Tröpfchen schmelzend und schwerlöslich in heilsem Wasser. Mit basisch essigsaurem Blei gibt das Ammoniaksalz der Säure sogleich einen dicken, weilsen, käsigen Niederschlag, leicht- 
löslich in Säuren und in einem Ueberschufs des Fällungsmillels. Salpetersaures Silber wird vom Anımoniaksalz ebenfalls in weifsen, der frisch gefallten Thonerde sehr ähnlichen Flocken präcipilirt.

Alle angeführten Eigenschaften slimmen so vollkommen mit den Eigenschaften der Brenzweinsäure überein, wie sie von Pelouze angegeben worden sind, dafs ich, in Rücksicht auf ihre gleiche Zusammensetzung, durchaus kein Bedenken trage, die durch Oxydation der Feltsäure erhaltene Säure mil der Brenzweinsäure für vollkoummen identisch zu erklären. Von den Angaben Weniselos weichen die meinigen nur in Betreff des Ammoniaksalzes, welches ersteres krystallisirl und in Betreff des Blcisalzes ab, welches sich nach demselben nach einiger Zeit in kleinen Nadeln absetzen soll, während Pelouze, so wie ich, unter denselben Verhällnissen nur körnige Niederschläge erhielten.

Zur Alongewichtsbestimmung wählte ich das Silbersalz, welches durch Fällen des salpetersauren Silberoxyds mit dem Ammoniaksalz der Säure dargestellt wurde, es gelang mir übrigens nicht, dasselbe von constanter Zusammenselzung zu erhalten, was sich aber daraus erklären läfst, dafs das Ammoniaksalz beim Alıdampfen Ammoniak verliert; ich lekam bei zwei verschiedenen Darstellungen 2--3 pC. Silberoxyd zu wenig, während die damit verbundene Säure, nach Abzug des Silberoxyds für sich berechnet, ziemlich genau der Formel der wasserfreien Säure entsprach.

Das Silbersalz ist sehr emplindlich gegen das Licht, trocknet langsam und bildet dann durchscheinende harte Stücke, sehr ähnlich dem getrockneten Thonerdehydral; zerrieben geben dieselben ein bräunlichweifses Pulver.

Die Analyse gab folgende Resultate :

I. Bereitung, 1) 0,3358 Grin. Substanz gaben 0,2005 Ag $=0,2153 \mathrm{AgO}$.

2) 0,4038 Grm. Subst. gaben $0,2415 \mathrm{Ag}=0,2585 \mathrm{Ag0}$. 
3) 0,6715 Grm. Subst. gaben, mit chroms. Bleioxyd verbrannt, 0,465 Kohlensäure und 0,1245 Wasser.

II. Bereitung. 1) 0,3355 Grm. Subst. gaben 0,2027 Ag $=0,21777 \mathrm{AgO}$.

2) $1,0034 \mathrm{Grm}$. Subst. gaben bei der Verbrennung 0,675 Kohlensäure und 0,178 Wasser.

In 100 berechnet gleich :

\begin{tabular}{|c|c|c|c|c|}
\hline \multicolumn{3}{|c|}{ I. Bereitung } & \multicolumn{2}{|c|}{ II. Bereitung } \\
\hline $\begin{array}{l}\text { I. } \\
64,11\end{array}$ & 64,01 & III. & $\frac{1 .}{64,88}$ & II. \\
\hline$\gg$ & " & 18,88 & 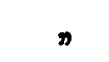 & 18,34 \\
\hline " & 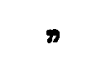 & 2,06 & $\Rightarrow$ & 1,97 \\
\hline$n$ & " & 》 & $\pi$ & $n$ \\
\hline
\end{tabular}

Dem brenzweinsauren Silberoxyd würden entsprechen :

\begin{tabular}{|c|c|c|}
\hline $1 \mathrm{AgO}$ & 1450 & 67,05 \\
\hline $5 \mathrm{C}$ & 375 & 17,35 \\
\hline 3 H & 37,5 & 1,73 \\
\hline 30 & 300,0 & 13,87 \\
\hline $\mathrm{AgO}, \overline{\mathrm{C}_{5} \mathrm{H}_{3} \mathrm{O}_{3}}$ & 2162,5 & 100. \\
\hline
\end{tabular}

Bringt man bei der oben angeführten Anaiyse den Mittelwerth des gefundenen Silheroxydgehalts in Abzug und berechnet die damit verbundenen Kohlenstoff -, Wasserstoff - und Sauersloffelemente auf 100 , so erhält man genau die procentischen Zahlen der Pyroweinsäure, wie sich aus folgender Zusammenstellung ergibt :

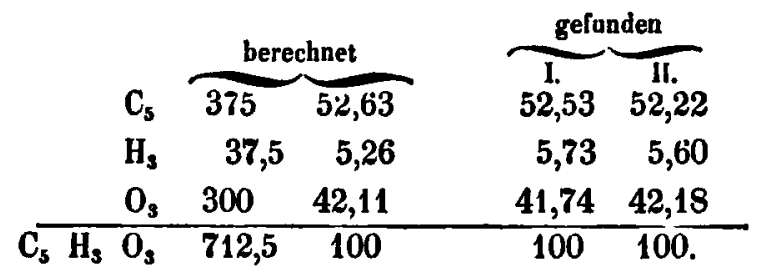

Es wurde ferner noch der Bleiniederschlag analysirt, welcher durch Bleiessig in dem Ammoniaksalz der Säure hervorgebracht wird. Wie erwähnt, entsteht ein dicker, käsiger 
Niederschlag, welcher nach einigen Slunden auf dem Boden des Glases zu einer schwach gelblichen, harten und zerreiblichen Kruste zusammenbackt. Derselbe wurde bei $100^{\circ}$ getrocknet und analysirt.

1) 0,321 Grm. Substanz gaben $0,3195 \mathrm{PbO} \mathrm{SO}_{5}$.

2) $0,4655, \pi, 0,460, \pi$

3) 0,3588 ,, von verschiedener Bereitung gaben $0,3555 \mathrm{PbO} \mathrm{SO}_{3}$.

Diesem Bleigehalte entspricht genau die Formel :

$\mathrm{C}_{10} \mathrm{H}_{7} \mathrm{O}_{7}+3 \mathrm{PbO}=2\left(\mathrm{PbO}, \mathrm{C}_{5} \mathrm{H}_{3} \mathrm{O}_{3}\right)+\mathrm{PbO} \mathrm{HO}$, wie sich aus der Zusammenstellung der gefundenen und berechneten Werthe ergibt :

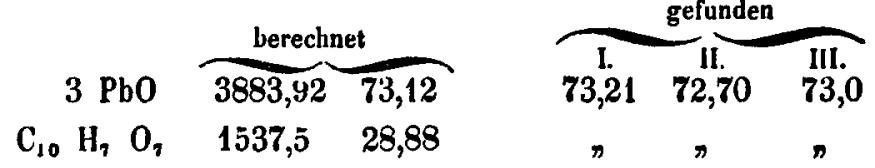

Eine weitere Vergleichung dieser Säure mit der Brenzweinsäure wird erst dann möglich, wenn lelztere einer gründlicheren Untersuchung unterworfen worden ist; obgleich schon in Folge der obigen Angaluen kaum melir an der Identität beider Säuren gezweifelt werden kann *).

*) Der Hr. Verfasser, welcher sich seit länger als einem Jahr in Amerika aufhält, lconnte zur Zeit der Abfissung dieser Mittheilung von der Untersuchung der Brenzweinsäure von Hrn. Arppe (diese Annal. LXVI, 73) keine Kenntnifs haben.

d. $\mathbf{R}$. 